Int. J. Electrochem. Sci., 15 (2020) 8979 - 8989

\title{
Mechanism of Chromium Electrodeposition from Cr(III) Baths on Nickel and Chromium Electrode Surfaces
}

\author{
Huan Zhao ${ }^{1,2, *}$, Weihua Liü, Qingpeng Li $^{2}$, Bo Zhang ${ }^{2}$, Jianguo Liu ${ }^{2}$, Chuanwei Yan ${ }^{2}$, Chunming Liu ${ }^{1}$ \\ ${ }^{1}$ School of Materials Science and Engineering, Northeastern University, Shenyang 110819, China; \\ ${ }^{2}$ Institute of Metal Research, Chinese Academy of Sciences, Shenyang 110016, China \\ *E-mail: hzhao@imr.ac.cn
}

doi: $10.20964 / 2020.09 .23$

Received: 16 December 2019 / Accepted: 1 June 2020 / Published: 10 August 2020

The electrode state changes with the thickening of the coating in $\operatorname{Cr}(\mathrm{III})$ thick chromium plating. The deposition of $\mathrm{Cr}$ (III) is carried out on the substrate at the beginning of deposition and on the chromium coating when the chromium coating becomes thicker. The aim of this work is to study the influence of the change of electrode state on the reduction mechanism of trivalent chromium. The electrodeposition mechanism of $\mathrm{Cr}$ (III) is studied by cyclic voltammetry, electrochemical impendance spectroscopy, chronoamperometry and polarization technique. The results show that the reduction of $\mathrm{Cr}$ (III) on chromium coating electrode has a negative deposition potential, higher charge transfer resistance, higher activation energy, and lower diffusion coefficient than those on the nickel electrode, the reduction of $\mathrm{Cr}(\mathrm{III})$ is more difficult on chromium coating electrode. The change of electrode state is one of the reasons for the difficulty in thickening of chromium coating.

Keywords: Trivalent chromium; Hard chromium electrodeposition mechanism; Nickel electrode; Chromium coating electrode;

\section{$\underline{\text { FULL TEXT }}$}

(C) 2020 The Authors. Published by ESG (www.electrochemsci.org). This article is an open access article distributed under the terms and conditions of the Creative Commons Attribution license (http://creativecommons.org/licenses/by/4.0/). 